\title{
HISTÓRIA, TRABALHO E EDUCAÇÃO: RELAÇÕES DE PRODUÇÃo E QUALIFICAÇÃO DA FORÇA DE TRABALHO NA AGROINDÚSTRIA CANAVIEIRA $^{1}$
}

\author{
Manoel Nelito Matheus Nascimento ${ }^{2}$
}

\begin{abstract}
RESUMO:
Este estudo analisa as transformações na produção e as relações com os processos educativos gerais e de formação da força de trabalho, tendo por base a agroindústria canavieira. A análise está dividia em fases: a primeira abrange o período que vai do século XVI ao XIX. A lavoura da cana-de-açúcar e a produção do açúcar no engenho se realizavam com o trabalho escravo. A instrução escolarizada interessava apenas a uma pequena camada da elite. A segunda fase, a transição da produção no engenho para a usina, nas últimas décadas do século XIX, em processo concomitante à transição do trabalho escravo para o trabalho livre assalariado. A educação cumpria o papel estratégico de formadora do novo trabalhador. A terceira fase analisa a expansão acelerada da industrialização no processo de substituição de importação de mercadorias, a partir da década de 1930, momento em que surgiu a grande indústria brasileira e houve uma crescente absorção de grandes contingentes de operários qualificados. A educação geral e a educação técnica profissional passam a funcionar em redes. A quarta fase aborda a reestruturação da produção com ênfase na automação (robotização) dos processos produtivos, com mudanças radicais para o trabalho e a formação profissional. Conclui-se que as transformações nas formas de organização da produção e no trabalho engendram novos processos educativos, que se transformam à medida que o capitalismo avança, mudando as relações de produção e ampliando a divisão do trabalho.

Palavras-chave: História da educação, Trabalho, Educação, Educação profissional; Agroindústria canavieira.

\section{HISTORY, WORK AND EDUCATION: RELATIONS OF PRODUCTION AND QUALIFICATION OF THE WORKFORCE IN THE SUGAR CANE INDUSTRY}

\begin{abstract}
:
This study examines the changes in production and relations with the general educational processes and formation of the workforce, based on the sugar industry. The analysis is organized in four phases: the first covers the period from the sixteenth to the nineteenth century. The the farming of the sugar cane and the manufacturing production of the sugar were carried out by the slaved work. The instruction educated interested only a small layer of the elite. The second phase, the transition from production on the plantation to the sugar mill, the last decades of the nineteenth century, in a process concomitant with the transition from slave work to the wage-earning free work. The education fulfilled the strategically role of forming a new worker. The third phase examines the rapid expansion of industrialization in the process of import substitution of goods, from the 1930s, when it appeared the great Brazilian industry and there was an increased absorption of large numbers of skilled workers. The general education and the technical - professional education were consolidated in nets. The fourth phase mentions the reorganization of the production emphasizing the automation ("robotization") of the productive processes, with radical changes into the work and professional formation. The results of the study allow concluding that, the transformations in the forms of organization of the production in the work; produce new educative processes and these transform themselves while the capitalism advances, changing the production relations and extending the division of the work.

Keywords: History of education; work; Education; Professional education; Sugar industry.
\end{abstract}

Revista HISTEDBR On-line, Campinas, número especial, p. 273-282,ago.2010 - ISSN: 1676-2584 


\section{INTRODUÇÃO}

Este estudo da relação trabalho e educação foi realizado tendo por base o desenvolvimento histórico da agroindústria canavieira, com o objetivo de analisar as transformações das relações de produção e como estas foram determinantes para as necessidades e exigências aos processos educativos e de qualificação da força de trabalho. Buscou-se identificar as relações entre as transformações na produção canavieira e a formação educacional dos trabalhadores, acompanhando as características mais gerais do desenvolvimento histórico da educação brasileira.

No amplo quadro do desenvolvimento das relações de produção e das relações de trabalho no Brasil, por quase quatro séculos, a produção foi baseada no trabalho escravo, sendo que, somente nas últimas décadas do século XIX, a escravidão foi extinta, e se passou ao regime de trabalho assalariado. As relações de produção capitalista foram consolidadas ao longo do século XX, com a expansão da industrialização e a modernização da produção agrícola e, com elas, as relações de trabalho baseadas no assalariamento. Nas últimas décadas do século XX e na atual, uma nova fase de transformações nas relações de produção e nas políticas econômicas e sociais está em processo, com graves desdobramentos para os trabalhadores e para os processos educativos.

A escola moderna, criada no processo de desenvolvimento do modo de produção capitalista, torna-se a principal cumpridora da função educativa dos princípios de convivência em sociedade, tomando a educação escolar como a forma predominante de transmissão de conhecimentos na sociedade atual.

A universalização da escola primária promoveu a socialização dos indivíduos nas formas de convivência próprias da sociedade moderna, familiarizando-os com os códigos formais integrantes do universo da cultura letrada, e ao mesmo tempo capacitou-os, minimamente, a integrar o processo produtivo. A introdução da maquinaria eliminou a exigência de qualificação específica, mas impôs um patamar mínimo de qualificação geral, equacionado no currículo da escola primária (SAVIANI, 2000, p. 163).

Mas as funções educativas atribuídas à escola, no entanto, não se produzem de modo mecânico, por serem determinadas pelas contradições entre as classes sociais, visto que a divisão social do trabalho tem correspondência na divisão social da escola ao constituir escolas próprias para a elite e escolas diferenciadas para a grande massa de trabalhadores e seus filhos. Assim, a aclamada universalização da educação, processada na sociedade capitalista, dá-se de forma contraditória, por instituir escolas diferenciadas para classes sociais diferentes. Para uma pequena parcela da sociedade com a função de comando, há as escolas com formação intelectual e, para as massas, as escolas profissionalizantes, do aprender a fazer, com reduzida formação intelectual.

É também nesta direção que se coloca a análise de Frigotto (2003), que atribui ao trabalho um importante papel como princípio educativo, já que

[...] os processos educativos, escolares ou não, constituem-se em práticas sociais mediadoras e constituintes da sociedade em que vivemos. São práticas sociais não neutras. Eles podem, e têm feito, dominantemente, reforçar as relações sociais capitalistas que subordinam o trabalho, os bens da natureza, a ciência e tecnologia como propriedades privadas, valores de troca e a consequente alienação e exclusão de milhões de seres humanos da vida digna ou 
de sua radical transformação. Esses processos educativos têm o mercado e o capital como medida de tudo, em função do privilégio de poucos. Mas a história vem mostrando que eles podem se constituir em instrumento de crítica a essas relações sociais e, também, promotores de uma nova sociedade que afirme o ser humano como medida de todas as coisas e os bens do mundo como bens de uso de todos os seres humanos.

Neste sentido, a relação trabalho-educação no âmbito da agroindústria canavieira é abordada neste estudo numa perspectiva histórica, por se considerar necessária a análise histórica não apenas para desvelar o passado, mas para a análise e compreensão do mesmo objeto de estudo no processo histórico contemporâneo. Desta forma, busca-se analisar as transformações das relações de produção ao longo do desenvolvimento da agroindústria canavieira, na tentativa de compreensão dos problemas atuais presentes na relação trabalho-educação.

A abordagem histórica da relação trabalho e educação se fundamenta na obra Contribuição para a crítica da economia política em que Marx afirma que "a história moderna e contemporânea é dominada pelo capital". Saviani (2004, p. 17) assinala que "não é possível, portanto, compreender radicalmente a história da sociedade contemporânea e, consequentemente, a história da educação contemporânea, sem se compreender o movimento do capital".

Para tanto, adota-se a concepção de homem como ser essencialmente social e histórico, que realiza a sua existência através do trabalho. O homem, movido por necessidades básicas e objetivas, age sobre o mundo para conhecê-lo, transformá-lo enquanto ao mesmo tempo se transforma. $\mathrm{O}$ conhecimento, como resultado desse processo de transformação da natureza e de si próprio, é um processo histórico dialético, socialmente construído. "Os homens fazem sua própria história, mas não a fazem como querem, não a fazem sob circunstâncias de sua escolha e sim sob aquelas com que se defrontam diretamente ligadas e transmitidas pelo passado" (MARX; ENGELS, 1987, p. 329).

Assim, na condução deste estudo, toma-se o trabalho como categoria fundamental para a análise da sociedade e como princípio educativo mediador das relações entre os homens, determinando e condicionando a produção da vida, as formas de organização social, política, jurídica e ideológica.

A transformação da base material da sociedade, isto é, da divisão social do trabalho e das relações de trabalho a partir de suas próprias e inerentes contradições, resulta na transformação da sociedade, de suas formas de se estruturar e se organizar em todas as suas instâncias.

A educação é concebida como uma prática social, uma atividade humana e histórica que se define nos múltiplos espaços da sociedade, na articulação com os interesses econômicos, políticos e culturais dos grupos ou classes sociais. Para Saviani (2000, p. 151), "[...] a educação é funcional ao sistema capitalista, não apenas ideologicamente, mas também economicamente, enquanto qualificadora da mão-de-obra (força de trabalho)".

Em linha com este raciocínio trabalha-se com o pressuposto do sistema educacional estruturado com base no trabalho, por considerá-lo como a base da existência humana; por ser através do trabalho que o homem produz a sua própria existência. Trabalhar é agir sobre a natureza, agir sobre a realidade, transformando-a em função dos objetivos, das necessidades humanas 


\section{AS TRANSFORMAÇÕES NAS RELAÇÕES DE PRODUÇÃO E NOS PROCESSOS EDUCATIVOS E DE QUALIFICAÇÃO DA FORÇA DE TRABALHO}

Para efeito deste estudo, as transformações nas relações de produção e nos processos educativos e de qualificação da força de trabalho estão organizadas em quatro fases, que estão inseridas no processo geral de formação do modo de produção capitalista e correspondem às etapas de seu desenvolvimento, que foram descritas por Marx como: a manufatura e a grande indústria.

Na manufatura, os instrumentos e as técnicas de produção ainda são as mesmas da produção artesanal, na qual o trabalhador controla os meios e as técnicas de produção. Porém a produção manufatureira se caracteriza pelo trabalho coletivo por meio da cooperação e da especialização de algumas atividades.

$\mathrm{Na}$ etapa da grande indústria, há o emprego da maquinaria moderna. Enquanto a manufatura revolucionou o modo de produção através da força de trabalho, a indústria moderna revolucionou a produção através da introdução da máquina como ferramenta. "Reaparece então a cooperação peculiar à manufatura baseada na divisão do trabalho, mas agora sob a forma de combinação de máquinas-ferramenta parciais complementares." (MARX, 1996, p. 432).

A primeira fase corresponde ao longo período de mais de três séculos desde o início da colonização até o século XIX, quando a força de trabalho necessária na lavoura da canade-açúcar, na manufatura do açúcar no engenho e na produção artesanal dos banguês, foi suprido pelo trabalho escravo. A escravidão de negros africanos, intensamente explorada para suprir de braços a produção, tornou-se um elemento determinante na constituição da sociedade escravista brasileira.

No início da colonização, quando os primeiros engenhos foram instalados, as atividades especializadas dos mestres e contramestres na produção do açúcar eram realizadas por profissionais originários das colônias portuguesas e que tinham conhecimentos e experiências na produção sucro-alcooleira. No entanto, à medida que ocorreu um processo de divisão e simplificação do trabalho, houve a transferência de tarefas dos mestres para trabalhadores menos hábeis, em geral escravos, que aprendiam os ofícios por intermédio da convivência, da observação e de muito trabalho, sem padrões ou regulamentações.

A desqualificação do trabalho no âmbito do engenho foi uma consequência direta da divisão do trabalho e da desvalorização dos ofícios necessários à produção açucareira, nesse período de transição do artesanato para a manufatura os conhecimentos foram passados adiante sem qualquer regra ou controle, com as consequentes perdas de qualidade no processo. Em paralelo, houve a desvalorização do trabalhador, que deixou de ser reconhecido como detentor de um conhecimento especializado sobre a arte de produzir o açúcar e passou a ser apenas um trabalhador livre entre a escravaria que tinha dominado os mesmos conhecimentos. A contradição é que o escravo não se beneficiava ao assumir estas novas funções, apenas o senhor de engenho ganhava com a valorização de seu escravo e a não-necessidade de contratar o oficial de açúcar.

A manutenção do trabalho escravo inibiu as iniciativas para a instituição de escolas para a formação do trabalhador, tendo em vista que a sociedade escravista não valorizava o trabalho manual e não tinha quaisquer preocupações com a formação profissional. A educação escolar na Colônia esteve sob a responsabilidade da Igreja Católica até a segunda metade do século XVIII, e pouco avançou no ensino popular, visto que o principal objetivo 
era a formação de religiosos para compor seus quadros e o atendimento aos filhos da elite. Mesmo quando o Estado assumiu a responsabilidade pela oferta de ensino para as crianças, pouco foi realizado em termos educacionais até o final do século XIX.

A segunda fase se constitui na transição da produção manufatureira no engenho para a produção industrial nos engenhos centrais e nas usinas no período que compreende as últimas décadas do século XIX e as primeiras do XX.

No final do século XIX, a produção do açúcar no Brasil ainda era realizada com métodos e técnicas arcaicos, herdados do período colonial, com um atraso tecnológico que tinha por consequência a baixa produtividade e qualidade. As inovações tecnológicas que revolucionaram a produção no século XIX foram introduzidas na produção de açúcar no Brasil somente no final do século, com a implantação dos engenhos-centrais, que eram fábricas compostas com equipamentos novos e de maior capacidade de produção.

A transição da produção artesanal nos banguês ou da manufatureira no engenho para a produção industrial no engenho-central e na usina no final do século XIX, concomitante à transição do trabalho escravo para o trabalho assalariado, trouxe com ela todas as demais características da exploração capitalista do trabalho. A mentalidade escravista que prevaleceu na sociedade brasileira até as últimas décadas do século XIX não permitiu a ampliação de oportunidades de ensino escolar à população em geral. Essa situação só começou a mudar nas últimas décadas, quando se extinguiu a escravidão e uma grande quantidade de imigrantes europeus foram trazidos para substituir a mão-de-obra escrava, com o estabelecimento de novas relações de trabalho, nova concepção social do trabalho e nova forma de regulação do trabalho. Nas usinas de cana de açúcar, seguindo o modelo adotado nos cafezais, prevaleceu o colonato como regime de trabalho.

No contexto de final de século XIX, com crescimento econômico proporcionado pelo sucesso do café, a expansão das indústrias voltadas para atender ao mercado interno em substituição aos produtos importados, a consolidação do regime de trabalho assalariado, a educação assumiu o papel estratégico de formar o novo trabalhador para atendimento de todas as demandas do emergente sistema produtivo brasileiro, sob o capitalismo monopolista e imperialista que avançava no país.

Algumas instituições escolares foram criadas nas últimas décadas do século XIX, tanto por iniciativa pública como privada, como as redes de grupos escolares em vários Estados. Em São Paulo, os grupos escolares datam de 1892. Ainda nesse período criaramse por iniciativa de grupos privados, os Liceus em São Paulo e no Rio de Janeiro, para o ensino dos ofícios.

As escolas públicas de ensino profissional surgiram somente na primeira década do século XX, quando a emergente industrialização se expandia. Em nível federal, elas foram criadas em 1909 e no Estado de São Paulo em 1911. No entanto, nessas experiências iniciais, a formação profissional ainda tinha o "caráter assistencialista", mais com o objetivo de retirar as crianças órfãs e desamparadas das ruas e dar-lhes alguma qualificação para ocupá-las.

A terceira fase se desenvolve a partir de 1930, com o aceleramento da industrialização do país, e consolida-se na década de 1970, com o fim da chamada de "industrialização via substituição de importações".

No âmbito da expansão da industrialização nas primeiras décadas do século XX, com a crescente aplicação de novas tecnologias na produção e da intensificação das lutas do movimento operário, efetivou-se o movimento pela organização científica ou racional das atividades laborais. Além de mudar a organização do trabalho, os defensores dessa 
idéia também defendiam que era necessário mudar os processos de formação do homem para o trabalho. Na década de 1920, algumas experiências foram realizadas com a aplicação dos métodos racionais na qualificação do trabalhador, até conquistar novas áreas de aplicação na educação. A hegemonia dos liberais reformadores e dos educadores da renovação educacional, no comando da educação em vários Estados do país, possibilitou que as inovações racionalizadoras fossem introduzidas na rede pública de ensino profissional em 1933. A partir de então, a aprendizagem sistemática de ofício foi generalizada em nível nacional, influenciando, no início da década de 1940, as reformas educacionais que reorganizaram a sistema educacional brasileiro.

Esse movimento correspondia à expansão acelerada da industrialização no Brasil que, como se sabe, foi um processo que se deu em decorrência da substituição de importação de mercadorias, iniciando uma fase de absorção de grandes contingentes de operários qualificados para operar, manter e reparar os equipamentos, assim como o pessoal encarregado de planejamento e controle. As Leis Orgânicas do Ensino foram instituídas, a partir de 1942, para atender à crescente demanda por mão-de-obra qualificada. A Lei para o Ensino Industrial, a primeira a ser instituída, criou o sistema de ensino profissional para a indústria. A Lei Orgânica do Ensino Industrial deslocou todo o ensino profissional para o grau médio, enquanto o ensino primário tornou-se exclusivamente propedêutico. Nesse período, ainda havia a restrição de acesso ao ensino superior, por ser permitido somente para os concluintes do propedêutico, visto que os egressos dos cursos profissionais não tinham o mesmo direito. A equivalência do ensino profissional com o propedêutico, dando os mesmos direitos de acesso aos níveis superiores de ensino, aconteceu somente em 1961, com a primeira Lei de Diretrizes e Bases da educação brasileira. Nesta mudança, a educação profissional deixava de ser apenas uma alternativa de educação para os pobres, e passava a ser importante estratégia para o desenvolvimento econômico e social. Em seguida à Lei do ensino industrial, foi instituída uma Lei Orgânica para o Serviço Nacional da Indústria - SENAI, que privatizava o ensino técnico profissional para a indústria, transferindo para o setor privado a responsabilidade pela formação e qualificação da mão-de-obra necessária para a expansão da industrialização. A criação do SENAI consolidava o projeto do setor produtivo de ter um sistema de ensino técnico profissional sob a sua administração, porém, financiado pelo Estado, com os impostos retidos.

Nesse período, processava-se a modernização capitalista da agricultura brasileira, iniciada na década de 1950, pela substituição dos meios de produção tradicionais por máquinas e insumo industriais, que implicou em nova divisão social do trabalho. Para dar suporte e difundir os conhecimentos e habilidades necessários para lidar com as tecnologias modernas de produção agrícola, o Governo brasileiro implementou os serviços de assistência técnica e Extensão Rural, para atuação junto aos produtores e trabalhadores rurais.

O programa de Extensão Rural tinha uma concepção de educação que revela a sua verdadeira função de instrumento de controle social e de desqualificação do conhecimento do produtor. A Extensão Rural considerava o produtor moderno como aquele que aceitava e incorporava as orientações dos técnicos, e não só se reconhecia devedor, como propagava a eficácia dos novos conhecimentos, atrelados ao conceito de produção de alimentos com produtividade e qualidade. A modernização implicava a desqualificação imediata do saber do produtor em favor do saber científico ou técnico. Nesse período, que a modernização conservadora da agricultura provocou significativas mudanças na produção rural, sobretudo com a expansão na utilização das terras e a crescente mecanização das 
atividades laborais, provocando a expulsão do trabalhador rural residente (os colonos) para a periferia dos centros urbanos e promovendo a proletarização do trabalhador rural.

No final da década de 1960, a ditadura militar iniciou a reforma da educação brasileira, com o objetivo imediato de atender às demandas das transformações na estrutura econômica do país e responder às pressões sociais pela ampliação de escolas e vagas na rede pública. Inspirada pela concepção produtivista de educação, a reforma educacional adotou como princípios básicos a racionalidade e a produtividade, e tinha como pretensões o estabelecimento de uma relação direta entre os sistemas produtivo e educacional, tendo como principal função da educação a qualificação para o mercado de trabalho, Em sintonia com esta concepção, a Reforma do Ensino Primário e Médio, através da Lei 5692/1971 instituiu a profissionalização compulsória no ensino de $2^{\circ}$ grau.

A quarta fase surge no final do século XX com o processo de transformação do capitalismo, que se desenvolve devido à reestruturação da produção mediante automação (robotização) dos processos produtivos, isto é, a transferência do trabalho humano (vivo) para as máquinas (trabalho morto), transformando radicalmente o trabalho e o processo de formação profissional.

Esta nova fase de crise e de transformações do capitalismo internacional iniciada na década de 1970, atingiu efetivamente o Brasil a partir de 1990, quando mercado interno foi aberto à economia internacional A reestruturação da produção, com ênfase na automação (robotização) dos processos produtivos, ampliando a transferência do trabalho humano (trabalho vivo) para as máquinas (trabalho morto), provocou mudanças radicais nas relações de trabalho e na formação profissional dos trabalhadores. Com a reestruturação da produção, a economia brasileira continuou o processo de integração à economia mundial, mas com novas consequências radicais para o trabalho, como a precarização das relações de trabalho, a geração de altos índices de desemprego e alterações nas políticas trabalhistas, com redução dos direitos e benefícios sociais ao trabalhador. A educação, também, sofreu transformações, no sentido de adaptação aos novos parâmetros do setor produtivo, por meio das várias reformas educacionais e da criação de novos cursos de formação para o trabalho, que têm sido instituídas nas décadas de 1990 e atual

Nesse contexto de rápidas mudanças em todos os setores da sociedade e do predomínio do padrão de produção caracterizado pela acumulação flexível, as ações educativas escolares e não-escolares se transformaram na busca de respostas aos novos requisitos do capital. Essas transformações afetaram profundamente a educação profissional, devido às mudanças dos processos de trabalho e das formas de sua organização e gestão, que tornaram superadas as formas tradicionais de educação profissional com referência nos moldes rígidos do regime de produção taylorista / fordista.

No modelo da acumulação flexível, o trabalhador não tem garantias de inclusão nas diversas formas de organização do trabalho, já que a utilização de sua força de trabalho é determinada pelas necessidades da produção. Assim, para a utilização flexível da força de trabalho, não é relevante o nível de qualificação do trabalhador e sim a sua capacidade de responder a exigências variadas da produção. Por esta razão, o capital prefere o trabalhador polivalente, dotado de múltiplas competências, apto para atuar em diversos postos de trabalho.

Contraditoriamente, ainda que o consumo flexível das competências ocorra de acordo com as necessidades da produção, tem sido recorrente o discurso da necessidade de ampliação dos níveis de escolaridade dos trabalhadores. Esse discurso tem se generalizado na sociedade, porém encobre a estratégia do capital em ampliar a reprodução do exército de reserva da força de trabalho. 
Nessa fase de reestruturação da produção, foram criados novos cursos para os trabalhadores do setor canavieiro, com as características do modelo da acumulação flexível, tendo por principal objetivo dotar o trabalhador de algumas competências que atendam às necessidades do setor, sem qualquer preocupação em ofertar uma formação integral.

Apesar das conquistas dos trabalhadores da agroindústria canavieira ao longo de sua história, verifica-se que ainda há registros de inúmeros casos de não cumprimento da legislação trabalhista, como a existência, ainda, de trabalho escravo, de trabalho degradante e a extrema exploração da força de trabalho, levada a efeito pelas ameaças dos produtores de cana de aumentar o número de máquinas colheitadeiras se os cortadores não cumprirem as metas de produtividade no corte da cana e, com isso reduzir o número de trabalhadores contratados. Essa situação se constata frequentemente na fase atual de expansão da agroindústria canavieira, em que a pressão sobre os cortadores de cana para aumentarem a produtividade,sob a ameaça da mecanização do corte, tem provocado muitos acidentes e casos de morte.

O setor produtivo da cana reflete bem o contraste presente na sociedade brasileira, com usinas utilizando tecnologias avançadíssimas tanto na agricultura quanto na fábrica, enquanto promove a superexploração do trabalho humano até o ponto que ainda é vantajoso em relação à utilização de máquinas. A superexploração do trabalhador ocorre sobretudo, na lavoura canavieira, nas atividades de colheita manual da cana-de-açúcar. No Estado de São Paulo, a maior parte do corte manual da cana-de-açúcar é realizada por trabalhadores migrantes da região Norte, que se deslocam por mais de quatro mil quilômetros, para se sujeitarem ao trabalho árduo do corte da cana-de-açúcar, sobrevivendo em condições precárias, em muitos casos desumanas ou até sob a forma da escravidão.

Em síntese, os elementos característicos do desenvolvimento histórico das relações de produção e dos processos educacionais, no setor canavieiro, verificados ao longo deste estudo, ainda persistem, apesar dos extraordinários resultados econômicos, do emprego de alta tecnologia na produção e da propagação de uma imagem de modernidade e de progresso.

Verificou-se que os principais elementos característicos das relações de produção na agroindústria canavieira estão presentes em todas as fases do desenvolvimento histórico desse setor produtivo e podem ser sintetizados na tendência à divisão, simplificação e desqualificação do trabalho, decorrente dos processos de simplificação e divisão das atividades produtivas, com a consequente transferência aos proprietários dos meios de produção dos conhecimentos produtivos exigidos do trabalhador, pela crescente incorporação da ciência, da tecnologia e da técnica à produção; pelo avanço tecnológico e que tem justificado altos índices de desemprego e exigência de maior nível de escolaridade; nas mudanças ideológicas do conceito de trabalho, em conformidade com os interesses do capital, gerando a necessidade de se afirmar que o trabalho é um elemento constitutivo do ser humano, que por meio dele, produz e reproduz a sociedade, transformando a si mesmo e aos outros homens. Soma-se a esses elementos característicos das transformações do trabalho, a histórica super-exploração dos trabalhadores em inúmeras situações, como a persistência de trabalho degradante e super-explorado, quer na forma de exploração de trabalho escravo ou no uso de trabalhadores assalariados.

As transformações na produção geraram impactos diretos no sistema educacional, criando a necessidade de adequação da força de trabalho às demandas do setor produtivo. Apesar das continuas mudanças nas atividades produtivas, em função do avanço 
tecnológico ao longo do tempo, tem se mantido o discurso da necessidade de maiores níveis de escolaridade para os novos postos de trabalho gerados com o avanço das novas tecnologias. No entanto, há uma postura contraditória dos representantes do capital e do próprio Estado quanto ao discurso que prega a necessidade de maiores níveis de escolaridade para a promoção do desenvolvimento social. Assim, a existência de relações históricas entre as transformações nas relações de produção e nos processos de formação da força de trabalho se configuram à medida que as forças produtivas e as relações de trabalho se transformaram pelo avanço do capitalismo, pela contínua divisão e simplificação do trabalho decorrente do avanço tecnológico na produção, determinando o surgimento de novas exigências na qualificação dos trabalhadores.

No entanto, ressalta-se que essas novas exigências nem sempre correspondem ao nível de conhecimentos efetivamente necessários para a execução do trabalho. Historicamente, houve (e há) a imposição ideológica de exigência de escolaridade elevada, enquanto o trabalho humano foi (e continua a ser) expropriado de conteúdo pela extrema divisão e simplificação da produção. Considera-se que, desta maneira, as forças do capital conseguem adequar os processos de qualificação do trabalhador às exigências da produção de acordo com o grau de avanço técnico e tecnológico, e realizar o controle social dos trabalhadores à medida que a exigência de maior escolaridade reduz o número de candidatos na disputa pelas poucas oportunidades de trabalho qualificado e amplia o exército de reserva de trabalhadores em processos de qualificação, os quais para obter o status de empregável, participam de inúmeros cursos de formação profissional, de requalificação, de especialização,...

\section{REFERÊNCIAS:}

ANTUNES, R. Trabalho e superfluidade. In: LOMBARDI, J. C.; SAVIANI, D.;

SANFELICE, J.L. (Orgs.). Capitalismo, trabalho e educação. 2 ed. Campinas: Autores Associados / HISTEDBR, 2004, p. 35 - 44

ANTUNES, R. Os sentidos do trabalho: ensaio sobre a afirmação e a negação do trabalho São Paulo: Boitempo, 2000.

ANTUNES, R. Adeus ao trabalho? Ensaio sobre as metamorfoses e a centralidade do mundo do trabalho São Paulo: Cortez/Unicamp, 1997.

KUENZER, A. Z.. O ensino médio agora é para a vida: entre o pretendido, o dito e o feito. Educação e Sociedade. Campinas: Cedes, ano XXI, n.70, abril 2000. p. 15-39.

MARX, K. O Método da Economia Política. In.: Manuscritos econômico-

filosóficos e outros textos escolhidos. São Paulo : Abril Cultural, 1974b.

MARX, K. O capital: crítica da economia política. Coordenação e revisão de Paul Singer. Tradução de Regis Barbosa e Flávio R.Kothe. São Paulo: Nova Cultural, 1996. (Os Economistas).

MARX, K. ; ENGELS, F. A ideologia alemã (Feuerbach). 6. ed. São Paulo: Hucitec, 1987

RIBEIRO, M. A. R.. Qualificação de Forca de Trabalho: A Experiência das Escolas Profissionais do Estado de São Paulo 1911/1942 In: RIBEIRO, Maria Alice Rosa (Org.). 
Trabalhadores Urbanos e Ensino Profissional. 2 ed., Campinas: Editora da UNICAMP, 1986

SAVIANI, D. Transformações do capitalismo, do mundo do trabalho e da educação. In: LOMBARDI, J. C.; SAVIANI, D.; SANFELICE, J.L. (Orgs.). Capitalismo, trabalho e educação. 2 ed. Campinas: Autores Associados / HISTEDBR, 2004, p. 13 - 24

SAVIANI, D. O trabalho como princípio educativo frente às novas tecnologias, In: FERRETTI, C. J.; et al (Orgs.) Novas tecnologias, trabalho e educação: um debate multidisciplinar. Ed. 6. Petrópolis, RJ: Vozes, 2000

1 Este texto apresenta uma síntese da tese "História, Trabalho e Educação: relações de produção e qualificação da força de trabalho na agroindústria canavieira" defendida na Faculdade de Educação da UNICAMP, que foi desenvolvida no âmbito do Grupo temático "História, Trabalho e Educação" integrante do Grupo de Estudos e Pesquisas "História, Sociedade e Educação no Brasil" - HISTEDBR. A tese está disponível na biblioteca online da UNICAMP e pode ser acessada pelo link: http://libdigi.unicamp.br/document/?code $=000447065$

${ }^{2}$ Doutor em Educação pela Faculdade de Educação da UNICAMP e professor do Departamento de Educação da Universidade Federal de São Carlos-UFSCar.

Recebido dia 10 de maio de 2010.

Aprovado dia 14 de junho de 2010. 